\title{
Prediction and evolution of transcription factors and their evolutionary families in prokaryotes Sarath Chandra Janga*1,2
}

Address: ${ }^{1}$ Program of Computational Genomics, Center for Genomic Sciences, UNAM, Cuernavaca, Morelos, Mexico, 62210 and ${ }^{2}$ MRCLaboratory of Molecular Biology, Hills Road, Cambridge, CB2 2QH, UK

Email: Sarath Chandra Janga* - sarath@mrc-lmb.cam.ac.uk

* Corresponding author

from BioSysBio 2007: Systems Biology, Bioinformatics and Synthetic Biology Manchester, UK. II-13 January 2007

Published: 8 May 2007

BMC Systems Biology 2007, I(Suppl I):P3 doi:I0.I I86/I752-0509-I-SI-P3

This abstract is available from: http://www.biomedcentral.com/I752-0509/I?issue=SI

(c) 2007 Janga; licensee BioMed Central Ltd.

Transcription factors (TFs) play an important role in the genetic regulation of transcription in response to internal and external cellular stimulus even in a simple bacterium like Escherichia coli [1]. However little is known about their functional roles, expression dynamics and evolutionary scenarios on a large scale, even in a well studied model organisms. In this short tutorial, I will first talk about the prediction of transcription factors, which form the core of the regulatory repertoires in prokaryotes, responsible for controlling the expression of genes/transcription units by binding to their cis-regulatory regions. I will present different commonly used sequenced-based approaches to predict TFs in prokarya and discuss a simple rule of thumb to identify the putative regulatory role played by a TF based on its protein sequence alone [2-6]. I will discuss on some important properties of prokaryotic TFs which distinguish them apart from rest of the protein coding genes. The second part of the talk would concentrate on the evolutionary conservation of TFs and TF families across genomes and the implications of the observations on the phenotypic adaptation of species to different niches $[3,7,8]$. Finally, I will discuss some future perspectives in this area of research.

\section{References}

I. Martinez-Antonio A, Janga SC, Salgado H, Collado-Vides J: Internalsensing machinery directs the activity of the regulatory network in Escherichia coli. Trends Microbiol 2006, I4(I):22-27.
2. Perez-Rueda E, Collado-Vides J: The repertoire of DNA-binding transcriptional regulators in Escherichia coli K-12. Nucleic Acids Res 2000, 28(8): I838-1847.

3. Moreno-Campuzano S, Janga SC, Perez-Rueda E: Identification and analysis of DNA-binding transcription factors in Bacillus subtilis and other Firmicutes-a genomic approach. BMC Genomics 2006, 7:147.

4. Madan Babu M, Teichmann SA: Evolution of transcription factors and the gene regulatory network in Escherichia coli. Nucleic Acids Res 2003, 31 (4): 1234-1244.

5. Kummerfeld SK, Teichmann SA: DBD: a transcription factor prediction database. Nucleic Acids Res 2006:D74-8I.

6. Perez-Rueda E, Collado-Vides J, Segovia L: Phylogenetic distribution of DNA-binding transcription factors in bacteria and archaea. Comput Biol Chem 2004, 28(5-6):34I-350.

7. Lozada-Chavez I, Janga SC, Collado-Vides J: Bacterial regulatory networks are extremely flexible in evolution. Nucleic Acids Res 2006, 34( I 2):3434-3445

8. Madan Babu M, Teichmann SA, Aravind L: Evolutionary dynamics of prokaryotic transcriptional regulatory networks. J Mol Biol 2006, 358(2):6|4-633. 